\title{
TexMi: Development of Tissue-Engineered Textile-Reinforced Mitral Valve Prosthesis
}

\author{
Ricardo Moreira, MSc, ${ }^{1}$ Valentine N. Gesche, Dipl. -Ing. (Univ.), ${ }^{2}$ Luis G. Hurtado-Aguilar, MSc, \\ Thomas Schmitz-Rode, MD, Julia Frese, Dipl. -Ing. (FH), ${ }^{1}$ Stefan Jockenhoevel, MD,,2 and Petra Mela, PhD ${ }^{1}$
}

Mitral valve regurgitation together with aortic stenosis is the most common valvular heart disease in Europe and North America. Mechanical and biological prostheses available for mitral valve replacement have significant limitations such as the need of a long-term anticoagulation therapy and failure by calcifications. Both types are unable to remodel, self-repair, and adapt to the changing hemodynamic conditions. Moreover, they are mostly designed for the aortic position and do not reproduce the native annular-ventricular continuity, resulting in suboptimal hemodynamics, limited durability, and gradually decreasing ventricular pumping efficiency. A tissueengineered heart valve specifically designed for the mitral position has the potential to overcome the limitations of the commercially available substitutes. For this purpose, we developed the TexMi, a living textile-reinforced mitral valve, which recapitulates the key elements of the native one: annulus, asymmetric leaflets (anterior and posterior), and chordae tendineae to maintain the native annular-ventricular continuity. The tissue-engineered valve is based on a composite scaffold consisting of the fibrin gel as a cell carrier and a textile tubular structure with the twofold task of defining the gross three-dimensional (3D) geometry of the valve and conferring mechanical stability. The TexMi valves were molded with ovine umbilical vein cells and stimulated under dynamic conditions for 21 days in a custom-made bioreactor. Histological and immunohistological stainings showed remarkable tissue development with abundant aligned collagen fibers and elastin deposition. No cell-mediated tissue contraction occurred. This study presents the proof-of-principle for the realization of a tissue-engineered mitral valve with a simple and reliable injection molding process readily adaptable to the patient's anatomy and pathological situation by producing a patient-specific rapid prototyped mold.

\section{Introduction}

$\mathbf{V}$ ALVULAR HEART DISEASE is a major health and socioeconomic burden worldwide with $\sim 300,000$ valve replacements performed annually. ${ }^{1}$ The main cause for heart valve disease in industrialized countries is of degenerative origin affecting predominantly the elderly. ${ }^{2}$ Mitral valve regurgitation together with aortic stenosis is the most common valvular heart disease in Europe ${ }^{3}$ and North of America. ${ }^{4}$ As the first preferred clinical therapy, mitral valve disease is preferably treated with reconstructive techniques, ${ }^{5}$ however, this often just postpones the problem and replacement is still required at a later stage. ${ }^{6}$ Although the reconstruction rate of the mitral valve pathology is commonly claimed to be greater than $90 \%, 7,8$ the German Society for Thoracic and Cardiovascular Surgery reported it to be only $64.4 \%$ in $2010 .^{9}$
Available mechanical and biological heart valve prostheses significantly improve the patient's life quality and expectancy, but they still present key limitations. Mechanical prostheses necessitate long-term anticoagulation therapy to avoid thromboembolic complications due to high shear stress, nonphysiological flow profile, and blood damage. A daily anticoagulation treatment is associated with an increased risk of serious hemorrhagic complications. ${ }^{10}$ Biological prostheses are prone to structural degeneration and therefore to the need of reoperations. Moreover, commercial prostheses are mainly designed to be implanted in the aortic position and do not take into account the particular hemodynamics of the native mitral valve ${ }^{11}$ and the importance of the chordae tendineae for the ventricular function. ${ }^{12,13}$ Direct consequences are the limited durability of the prostheses ${ }^{14}$ and the gradually decreasing ventricular pumping efficiency. ${ }^{15}$

\footnotetext{
${ }^{1}$ Department of Tissue Engineering and Textile Implants, Institute of Applied Medical Engineering, Helmholtz Institute, RWTH Aachen University, Aachen, Germany.

${ }^{2}$ Institut für Textiltechnik, RWTH Aachen University, Aachen, Germany.
} 
Tissue-engineered heart valves (TEHVs) with repair and remodeling capabilities could overcome the limitations of today's valvular prostheses. ${ }^{16,17}$ To date, TEHVs have been conceived only as semilunar valves for the aortic and pulmonary position. ${ }^{18,19}$ No attempt to produce a complete tissueengineered mitral valve has ever been reported in the literature.

In this study, we describe a simple injection molding method for the fabrication of a TEHV specifically conceived for the mitral position, based on fibrin as the cell carrier material. Fibrin is an attractive scaffold material because of its autologous origin, rapid polymerization, the tunable degradation using protease inhibitors, ${ }^{20}$ the autologous release of growth factors, ${ }^{21}$ and the manufacturability into complex three-dimensional (3D) geometries with homogeneous cell seeding. ${ }^{22}$ However, being a hydrogel, fibrin is mechanically weak and TEHVs based on fibrin could only be implanted in the low-pressure pulmonary circulation of animal models. ${ }^{23,24}$ A possible solution to this issue is the integration of a textile coscaffold. We have recently demonstrated that the combination of a warp-knitted bioresorbable mesh with a cell-laden fibrin resulted in the successful production and midterm application of a small-caliber vascular graft in the high-pressure arterial circulation. ${ }^{25}$ In the present study, the proof-of-principle of a tissue-engineered textile-reinforced mitral valve-TexMiis presented. In this study, a tubular warp-knitted mesh is used with the twofold advantage of defining the 3D geometry of the valve and enhancing the mechanical properties of the tissue. The tubular design recapitulates the key elements of the native mitral valve: annulus, asymmetric leaflets (anterior and posterior), and chordae tendineae, which guarantee the annular-ventricular continuity.

The TexMi valves were molded with ovine umbilical vein cells and stimulated under dynamic conditions for 21 days in a custom-made bioreactor. Tissue analysis was performed by histological and immunohistological staining of main extracellular matrix (ECM) proteins, collagen content assay, and burst strength measurements.

\section{Materials and Methods}

\section{Tubular mesh production}

A macroporous tubular textile mesh of medical-grade polyethylene terephthalate (PET) multifilament fibers was produced at the Institut für Textiltechnik on a custom-made double raschel warp-knitting machine, type DR 16 EEC/EAC (Karl Mayer Textilmaschinenfabrik). For the production of the mitral valve structure, a tüll-filet pattern was chosen to obtain suitable mechanical properties for the application. A needle gauge of E30 (30 needles per inch) and a course density of 12 loops/cm were chosen. Fifty-two PET yarns were processed into a tubular structure with a hexagonal pattern. The side of the six equilateral triangles composing the hexagon was $2 \mathrm{~mm}$. The Young modulus of the mesh was $110 \mathrm{MPa}$ in a good agreement with the value, Vesely and colleagues reported for healthy human mitral valve chordae tendineae $(132 \mathrm{MPa}){ }^{26}$ The mesh was thermostabilized at $200^{\circ} \mathrm{C}$ for $8 \mathrm{~min}$ at the desired diameter $(31 \mathrm{~mm})$.

\section{Cell isolation, culture, and immunocytochemistry}

A mixed population of smooth muscle cells (SMCs)/ fibroblasts was isolated from the vein of the ovine umbilical cord harvested in accordance with the European Convention on Animal Care. The tunica adventitia was completely removed. The vein tissue was washed with phosphate-buffered saline (PBS; Gibco), minced into 1-mm rings, following removal of endothelial cells by $1 \mathrm{mg} / \mathrm{mL}$ collagenase (Sigma), transferred into tissue culture flasks, and bathed in a primary cell culture medium (Dulbecco's modified Eagle's medium [DMEM]; Gibco) with 10\% fetal bovine serum (PAA Laboratories $\mathrm{GmbH}$ ) and $1 \%$ antibiotic-antimycotic solution (Gibco). To obtain a sufficient number, the cells were serially passaged up to five times using $0.25 \%$ trypsin/0.02\% EDTA solution (Gibco) and cultured in $5 \% \mathrm{CO}_{2}$ and $95 \%$ humidity at $37^{\circ} \mathrm{C}$. Before valve molding, the cell phenotype was verified by positive immunofluorescence staining for alphasmooth muscle actin ( $\alpha$-SMA) and the absence of the von Willebrand factor (vWf). The cells were fixed with ice-cold methanol $\left(-20^{\circ} \mathrm{C}\right)$ and rehydrated in PBS. Unspecific epitopes were blocked, permeabilized with normal goat serum (NGS; Dako), and incubated for $1 \mathrm{~h}$ at $37^{\circ} \mathrm{C}$ with the following primary antibodies: 1:400 mouse anti- $\alpha$-SMA (A 2547; Sigma) and 1:200 rabbit polyclonal anti-human vWf (A0082; Dako). Secondary antibodies were incubated for $1 \mathrm{~h}$ at $37^{\circ} \mathrm{C}$ : $1: 400$ mouse immunoglobulin $\mathrm{G}(\mathrm{H}+\mathrm{L})(\mathrm{A} 11005$; Invitrogen) and 1:400 rabbit immunoglobulin $\mathrm{G}(\mathrm{H}+\mathrm{L})(\mathrm{In}-$ vitrogen). The cells were counterstained with 4',6-diamino-2phenylindole (DAPI) nuclei acid stain (Molecular Probes) and observed with a microscope equipped for epi-illumination (AxioObserver Z1; Carl Zeiss $\mathrm{GmbH}$ ). Images were acquired using a digital camera (AxioCam MRm; Carl Zeiss $\mathrm{GmbH})$.

\section{Fibrin synthesis}

Lyophilized human fibrinogen (Calbiochem) was dissolved in purified water (Milli-Q ${ }^{\mathrm{TM}}$; Millipore) and dialyzed with a cut-off membrane (Novodirect) of 6000-8000 MW overnight against tris-buffered saline (TBS). The fibrinogen concentration following sterile filtration was estimated by measuring absorbance at $280 \mathrm{~nm}$ with a spectrophotometer (Spectronic Genesys $^{\mathrm{TM}}$ 6; Thermo Fisher Scientific $\mathrm{GmbH}$ ). The final concentration was adjusted to $10 \mathrm{mg} / \mathrm{mL}$ with sterile TBS. The fibrin gel component of the valve $(6.0 \mathrm{~mL}$ in total) consisted of $3.0 \mathrm{~mL}$ of fibrinogen solution $(10 \mathrm{mg} / \mathrm{mL})$, $1.2 \mathrm{~mL}$ of TBS containing $60 \times 10^{6}$ umbilical vein SMCs/ fibroblasts $\left(10 \times 10^{6}\right.$ cells $\left./ \mathrm{mL}\right)$, and $0.9 \mathrm{~mL} 50 \mathrm{mM} \mathrm{\textrm {CaCl } _ { 2 }}$ (Sigma) in TBS. Fibrin polymerization was initialized by adding $0.9 \mathrm{~mL}$ of thrombin solution ( $40 \mathrm{U} / \mathrm{mL}$; Sigma).

\section{TexMi concept, mold design, and production}

The TexMi design recapitulates the key elements of the native mitral valve: annulus, asymmetric leaflets (anterior and posterior), and chordae tendineae. It is produced by injection molding of fibrin embedding cells ${ }^{22}$ and a textile PET mesh. The mold was dimensioned and designed to reproduce the average annulus size and leaflet geometry according to literature data on human mitral valve anatomy. ${ }^{27,28}$ It was designed with the 3D computer aided design (CAD) software Pro/Engineer (Wildfire 5.0; Parametric Technology Cooperation) and produced by rapid prototyping technology (Eden 350v; Object). It consists of two outer shells and an inner cylinder on which the thermostabilized mesh is placed together with two silicone connectors (Fig. 

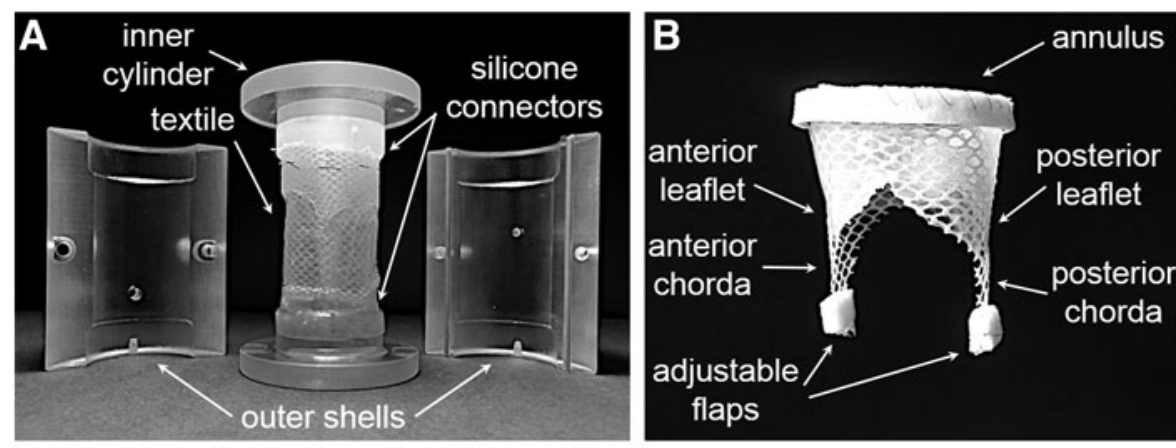

\section{C}

1

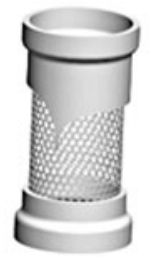

5

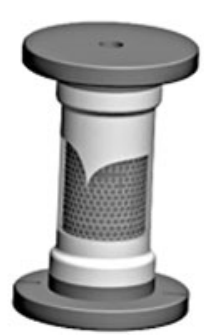

2

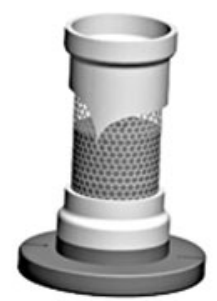

3

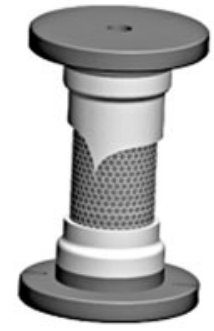

6

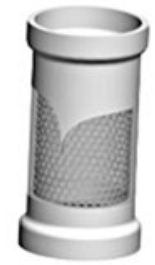

4

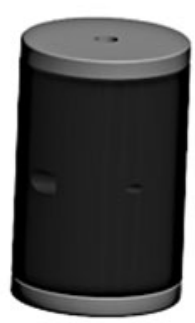

8

FIG. 1. Molding of TexMi. (A) Mold components, (B) TexMi valve after release from the mold, and (C) molding process: 1, tubular textile mesh with silicone components; $2-3$, textile scaffold on the bottom and top inner parts; 4 , assembled molding system in which the fibrin gel components are injected through a hole in one of the shells; 5-7, decasting of the fibrin construct after polymerization and definition of the chordae tendineae; 8 , obtained textile-reinforced fibrin-based valve with a silicone connector for handling and positioning into the bioreactor.

1A) obtained by procuring a two-component silicone rubber (Elastosil $^{\circledR}$; Wacker Chemie AG) in simple molds. One of the connectors is used to define the shape of the leaflets, and the other one has the function to facilitate subsequent handling and positioning of the valve into a bioreactor. The fabrication process is schematically shown in Figure 1C. Initially, the warp-knitted mesh is fixed to the silicone connectors by partially embedding it at the moment the twocomponent silicon rubber polymerizes and forms the connectors. This assembly ("1" in Fig. 1C) is positioned onto the inner cylindrical components of the molding system ("2-3" in Fig. 1C) and the outer shells are also assembled ("4" in Fig. 1C). The space between the inner parts and the outer shells defines the shape and thickness of the fibrin matrix. The cell-seeded fibrin-forming components are injected into the assembled molding system through a hole in one of the shells and let to polymerize for $45 \mathrm{~min}$. The mold is then disassembled (" 5 " in Fig. 1C) and the textilereinforced fibrin construct is released ("6" in Fig. 1C). The process ends with the definition of the chordae tendineae by cutting the excess mesh. Surgical flies (Pledget; Santec $\mathrm{GmbH}$ ) can be added at the annulus and chordae tendineae to facilitate the implantation (Fig. 1B).

\section{Bioreactor system and operation}

The valves $(n=3)$ were dynamically conditioned in a custom-made bioreactor (Fig. 2) consisting of two poly- methylmethacrylate (PMMA) chambers and a linear magnetic actuator (Typ810; Mönninghoff $\mathrm{GmbH}$ ) controlled through a custom-made LabVIEW ${ }^{\mathrm{TM}}$ application (National Instruments) displacing a silicone membrane and creating strokes with a defined shape mimicking the ventricular systole. The valves were positioned on a holder with the chordae tendineae sutured to flexible silicone beams (Elastosil) to enable closing and opening cycles. All PMMA bioreactor components were sterilized by low-temperature $\left(50^{\circ} \mathrm{C}\right)$ hydrogen peroxide gas plasma (STERRAD $100 \mathrm{~S}$ Sterilization System; Ethicon $\mathrm{GmbH}$ ) at least 4-5 days before use. Other components were sterilized at high temperature by autoclaving $\left(121^{\circ} \mathrm{C}\right)$. Videos of opening (diastole) and closure (systole) cycles were obtained by means of a high-speed camera (480 frames/s, Exilim EX-ZR100; Casio).

The valves were cultured in the low glucose DMEM supplemented with $10 \%$ fetal bovine serum, antibiotic/antimycotic solution, $1.0 \mathrm{mM}$ L-ascorbic acid 2-phosphate (Sigma), and $1.6 \mu \mathrm{L} / \mathrm{mL}$ tranexamic acid (CyklokapronInjection solution $1000 \mathrm{mg} / \mathrm{mL}$; Pfizer Pharma $\mathrm{GmbH}$ ) for 21 days at $37^{\circ} \mathrm{C}, 21 \% \mathrm{O}_{2}$, and $5 \% \mathrm{CO}_{2}$, according to the following protocol: 5 days in static cultivation, 6 days at 30 beats per minute (bpm), 6 days at $40 \mathrm{bpm}, 2$ days at $50 \mathrm{bpm}$, and 2 days at $60 \mathrm{bpm}$. The gas exchange was guaranteed by an external peristaltic pump (MCP Process; Ismatec), recirculating the medium in gas-permeable silicone tubes and by a gas filter connected to the compliance chamber. Culture 


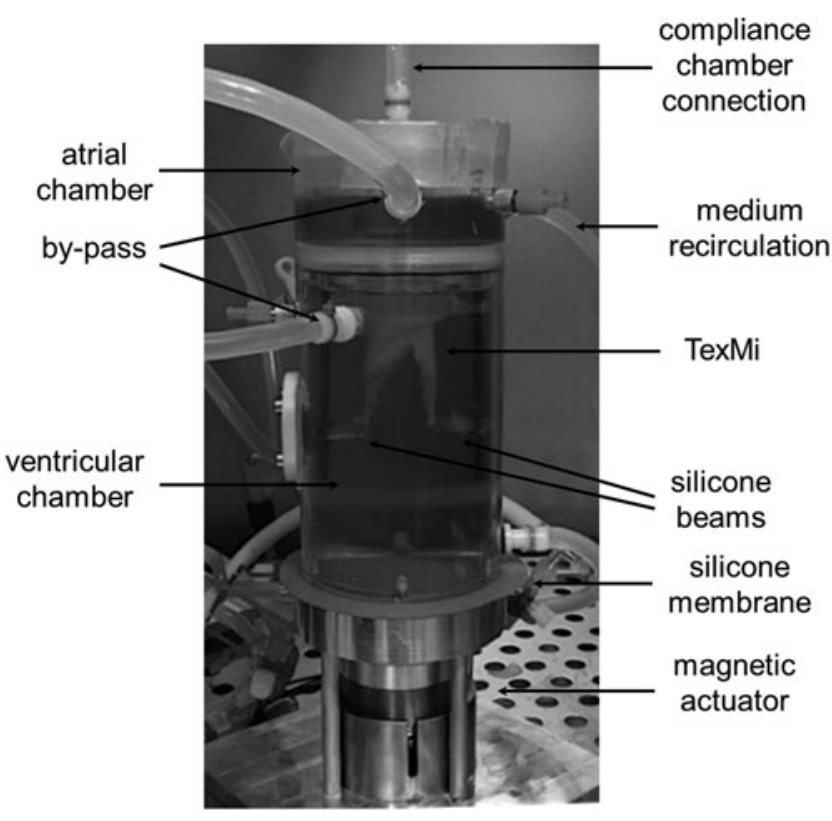

FIG. 2. Bioreactor system for conditioning of TexMi. The valve is mounted with the chordae tendineae sutured to silicone beams to enable closing and opening cycles.

conditions were monitored every 2 days by measurements of lactate and glucose concentration, $p \mathrm{O}_{2}, p \mathrm{CO}_{2}$, and $\mathrm{pH}$ by an automatic blood gas analyzer (Radiometer ABL 800 Flex; Radiometer Medical A/S). The culture medium was replaced every 6-7 days.

\section{Tissue analysis}

After conditioning, tissue samples were rinsed in PBS, fixed in Carnoy's fixative, and embedded in paraffin for subsequent histological analysis.

\section{Routine light microscopy}

Carnoy's fixed, paraffin-embedded native ovine and tissue-engineered mitral valves were sectioned at $3 \mu \mathrm{m}$ thickness longitudinally and stained by standard hematoxylin and eosin (H\&E) and Gomori's trichrome protocol for analysis of general tissue morphology and development. Sections were analyzed by routine brightfield microscopy (AxioImager D1; Carl Zeiss $\mathrm{GmbH}$ ) and images were acquired using a digital color camera (AxioCam MRc; Carl Zeiss $\mathrm{GmbH})$.
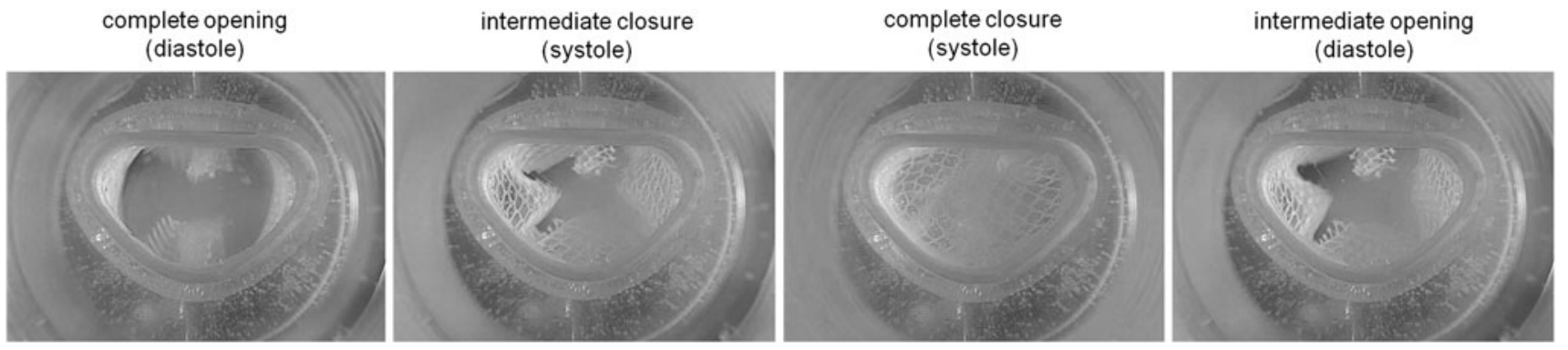

Immunohistochemistry

Nonspecific sites on Carnoy's fixed, paraffin-embedded sections from native ovine and tissue-engineered valves were blocked and the cells were permeabilized with 5\% NGS (Sigma) in $0.1 \%$ triton PBS. Sections were incubated for $1 \mathrm{~h}$ at $37^{\circ} \mathrm{C}$ with the following primary antibodies: 1:1000 mouse anti- $\alpha$-SMA (A 2547; Sigma); 1:200 rabbit anti-type collagen I (R 1038; Acris); 1:25 rabbit anti-type collagen III (R 1040; Acris); 1:200 rabbit anti-elastin (20RER003; Fitzgerald); and 1:60 rabbit polyclonal anti-human fibrinogen (F0111; Dako). The sections were incubated for $1 \mathrm{~h}$ at $37^{\circ} \mathrm{C}$ with either rhodamine or fluorescein-conjugated goat anti-mouse or goat anti-rabbit secondary antibodies: 1:400 mouse $\alpha$-SMA (A 11008; Molecular Probes); 1:400 rabbit type collagen I (A 11008; Molecular Probes); 1:300 rabbit type collagen III (E 0432; Dako); and 1:400 rabbit elastin (A 11008; Molecular Probes). Type collagen III signal was amplified by an additional incubation with 1:1000 streptavidin/TRITC (RA 021; Acris). The native ovine mitral valve served as a positive control. As negative controls, samples were incubated in diluent with the second antibody only. Tissue sections were counterstained with DAPI nuclei acid stain (Molecular Probes). Samples were observed with a microscope equipped for epi-illumination (AxioObserver Z1; Carl Zeiss GmbH). Images were acquired using a digital camera (AxioCam MRm; Carl Zeiss $\mathrm{GmbH})$.

\section{Burst strength measurements}

Burst strength values were determined with a custommade burst strength chamber equipped with a pressure sensor (Jumo Midas pressure transmitter; JUMO GmbH \& Co. KG) and a peristaltic pump (IPC Ismatec; IDEX Health $\&$ Science $\mathrm{GmbH})$. Samples $(n=3)$ of $1 \mathrm{~cm}^{2}$ area were placed onto the burst chamber and exposed to increasing pressure by pumping water until the structural failure of the sample occurred. This point was clearly detectable by a sudden drop in pressure and the highest pressure measured before failure was recorded as the burst strength value with a LabVIEW ${ }^{\mathrm{TM}}$ program (National Instruments).

\section{Quantification of collagen content (hydroxyproline assay)}

The hydroxyproline content of native ovine mitral valve and tissue-engineered samples $(n=3)$, dried under vacuum overnight, was determined as described by Reddy and Enwemeka. $^{29}$ A standard curve was generated using known

FIG. 3. Behavior of TexMi after 21 days of cultivation: still images from opening and closing cycles seen from the atrial side. 
amounts of trans-4-hydroxy-L-proline (Sigma). Native ovine mitral valve (anterior leaflet) served as a positive control.

\section{Results}

Evaluation of the valve's functionality was performed inside the bioreactor after 21 days of cultivation by recording the opening and closure cycles with a high-speed camera. Still frames at different times are presented in Figure 3. For visualization purposes, the medium was re- placed with PBS. The valve was able to close completely with an efficient leaflet coaptation and to open completely without flow restriction. Gross analysis of the valve demonstrated intact and flexible tissues with no noticeable tissue shrinkage.

\section{Tissue analysis}

Routine light microscopy. Brightfield microscopy images of cultivated TexMi are shown in Figure 4. H\&E staining
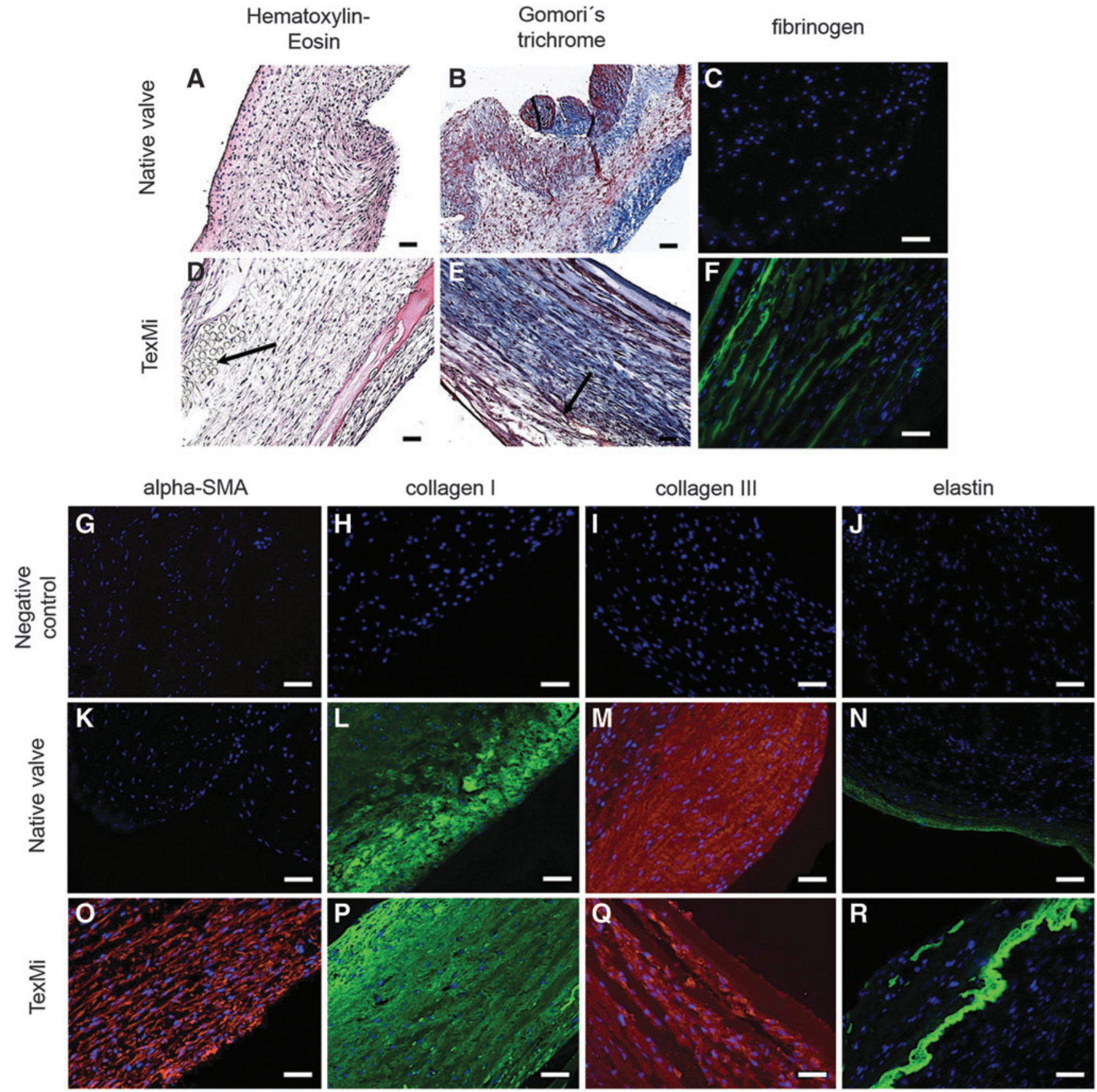

FIG. 4. Tissue analysis of TexMi. Hematoxylin and eosin and Gomori's trichrome of native ovine and tissue-engineered mitral valves' anterior leaflet (black arrows indicate the textile mesh) (A, B, D, E); immunohistochemical staining against fibrinogen $(\mathbf{C}, \mathbf{F})$, alpha-smooth muscle actin $(\alpha-\operatorname{SMA})(\mathbf{G}, \mathbf{K}, \mathbf{O})$, type collagen I $(\mathbf{H}, \mathbf{L}, \mathbf{P})$, type collagen III $(\mathbf{I}, \mathbf{M}, \mathbf{Q})$, and elastin $(\mathbf{J}, \mathbf{N}, \mathbf{R})$. DAPI (blue) was used as a cell nuclear counterstain in all samples studied. Scale bars: $50 \mu \mathrm{m}$. 
demonstrated a dense and homogeneous cell distribution throughout the valve's thickness with cells aligned longitudinally (Fig. 4D). Gomori's trichrome staining showed high collagen deposition, less pronounced on the side where the textile mesh was embedded (Fig. 4E).

Immunohistochemistry. Immunohistochemistry indicated the presence of $\alpha$-SMA in the developed tissue clearly showing the cell longitudinal alignment within the sample (Fig. 4O). There was extensive staining for type I and III collagen within the ECM of the tissue-engineered valve (Fig. 4P, Q) oriented along the longitudinal direction. Deposition of organized elastin is evident in Figure 4R. Staining against fibrinogen showed the presence of fibrin at the end of the cultivation time in the valve samples (Fig. $4 \mathrm{~F}$ ), whereas no fibrin was detected in the native mitral valve tissue (Fig. 4C). Negative controls for all markers reacted in the absence of the primary antibody showed undetectable levels of staining (Fig. 4G-J).

Burst strength. Burst strength testing is a common method to characterize the mechanical behavior of a tissue by determining the pressure at which structural failure occurs. The textile reinforcement resulted in an increased burst strength. The values for plain fibrin gel without and with textile reinforcement were $44.0 \pm 18.5 \mathrm{mmHg}$ and $90.7 \pm 14.0 \mathrm{mmHg}$, respectively. The burst pressure of TexMi valves was $554.7 \pm 92.2 \mathrm{mmHg}$ and the one obtained from native ovine mitral valve anterior leaflets was $5272.3 \pm 538.0 \mathrm{mmHg}$.

Hydroxyproline assay. The collagen content of TexMi valves was $9.1 \pm 2.0 \mu \mathrm{g} / \mathrm{mg}$, approximately half the amount found in the anterior leaflet of a native ovine mitral valve $(17.9 \pm 3.1 \mu \mathrm{g} / \mathrm{mg})$.

\section{Discussion}

This study presents a simple method for the realization of a tissue-engineered mitral valve-TexMi-with 3D geom- etry mimicking the native one, including the annulus, the asymmetric leaflets, and the chordae tendineae.

The valve design relies on a hybrid scaffold composed of fibrin as a cell carrier and a textile structure that defines the 3D geometry and enhances the mechanical properties of the valve. The TexMi is fabricated by injection molding. ${ }^{22}$ This simple and reliable process can be straightforwardly adapted to the patient's anatomy and pathological situation by producing a patient-specific rapid prototyped mold, on the base of computerized or magnetic resonance tomography of the native valve. The shape of the annulus can be easily varied maintaining the leaflet functionality, as shown in Figure 5AF. Furthermore, the molding process allows for the direct integration of a commercially available annuloplasty ring.

We showed the proof-of-principle by realizing a TexMi valve using cells derived from the ovine umbilical vein and subsequently conditioning it in a custom-made bioreactor. The chordae tendineae were fixed to silicone beams to condition the valve through functional opening and closing cycles. The applied cultivation conditions resulted in a wellorganized fibrous tissue structure with marked deposition of ECM. Type collagen I and III, the main protein components in native heart valves, were present throughout the whole specimen's thickness with a clear longitudinal orientation. Despite the relatively short cultivation time, there was significant collagen production and the tissue burst strength exceeded $500 \mathrm{mmHg}$. It is likely that a longer cultivation time (4-5 weeks), like generally performed for fibrin-based TEHVs, ${ }^{23,24,30}$ will result in a stronger tissue. Notably, immunohistology showed a remarkable synthesis of elastin oriented along the stress lines. Elastin has a fundamental function in heart valves. The lack of the formation of an organized elastic network in vitro has been reported as an issue in cardiovascular tissue engineering in general $^{31}$ and for TEHVs specifically, where hardly any elastin deposition has been shown in vitro. ${ }^{19}$ Notably, significant synthesis of elastin was recently shown in tissue-engineered vascular constructs obtained by rolling tissue sheets produced by cells isolated from human umbilical arteries, but not in those
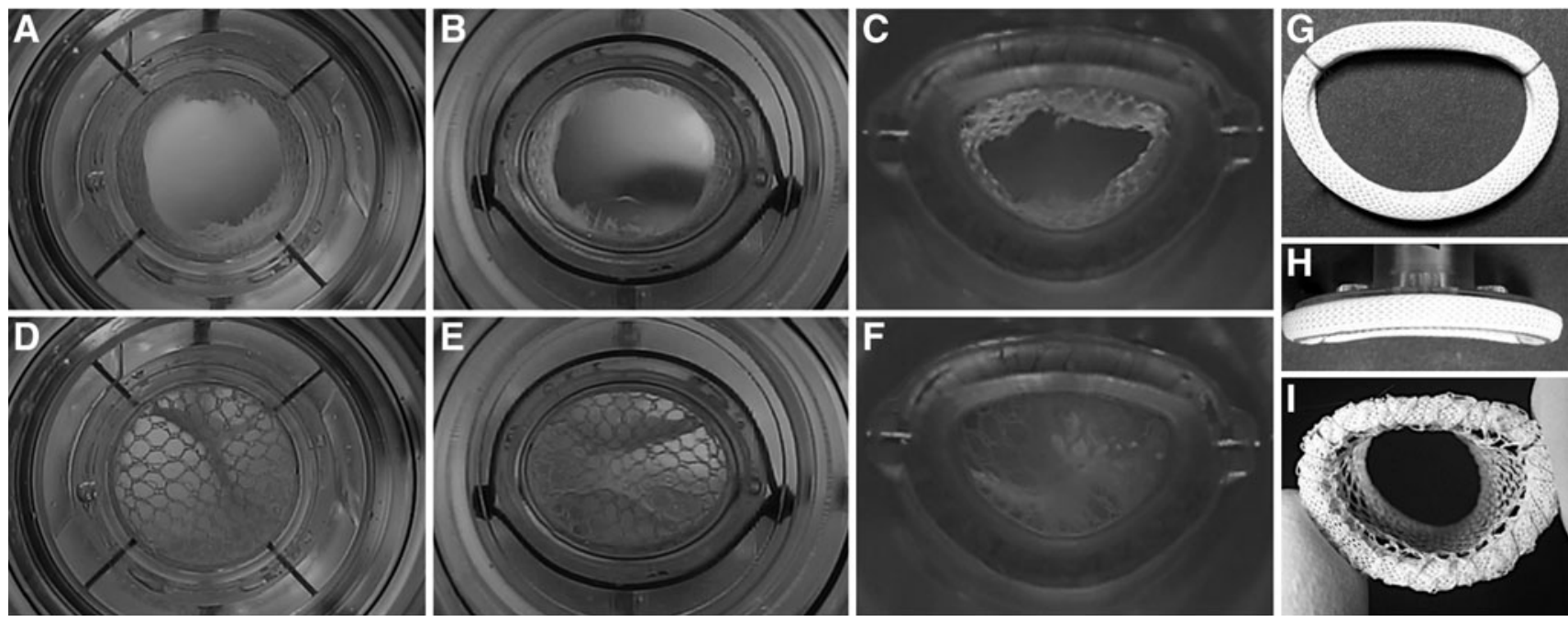

FIG. 5. TexMi valve in open and closed position with a circular (A, D), oval (B, E), and D-shaped annulus (C, F). The valve in $(\mathbf{C})$ and $(\mathbf{F})$ is supported by the Carpentier-Edwards Physio Annuloplasty Ring (Edwards Lifesciences) (G, H) sutured to the warp-knitted mesh (I). 
produced with cells isolated from human umbilical veins. ${ }^{32}$ Conversely, we did not observe elastin in TexMi produced with cells from the ovine umbilical arteries (not shown). Whereas our results with ovine cells cannot be directly compared to those with human cells, they confirm the importance of the cell source in TEHVs. ${ }^{28}$ Even more so, if we consider the cell-mediated tissue shrinkage, a major drawback of TEHVs and the main cause of valve failure. Whereas the TexMi produced with umbilical artery cells suffered marked tissue contraction, this did not happen with the TexMi from umbilical vein cells and the valve was perfectly functional after 21 days in vitro.

The mesh used in this study was rather basic, being composed of one material (PET) and having a coarse pore size. Warp-knitting technology enables to process different materials and combinations thereof as well as variable amounts and fineness of yarns. The pattern, pore size, and mechanical properties of the textiles are adjustable. ${ }^{33,34}$ It is reasonable to think that a more sophisticated textile structure combined with a longer cultivation time will result in enhanced mechanical properties of the valve. Ongoing research in our laboratory is aiming at the optimization of the textile coscaffold and at the complete integration of the textile chordae into the cell-laden fibrin gel during molding, to create tissue-engineered chordae as well. Besides their function in preventing leaflet prolapse during systole, the chordae provide valvular-ventricular continuity, which is of crucial importance for the efficiency of the left ventricular systolic function. Although this is largely accepted and surgically proven, ${ }^{5,12,13}$ the prostheses commonly used for mitral valve replacement are mainly designed for the aortic position and lack the anatomical distinct features of the native mitral valve. Only two substitutes, a mechanical and a biological one, have been developed specifically for the mitral position, both showing encouraging results in vivo. Daebritz et $a l .{ }^{35}$ have demonstrated the excellent hemodynamic performance and durability of a polycarbonate urethane prosthesis with two asymmetric leaflets (ADIAM Life Science AG). Walther et al. ${ }^{36}$ developed the SJM-Quattro-MV comprising four leaflets in the bovine pericardium that continue to form the chordae tendineae. Clinical tests performed in elderly patients have shown good hemodynamics, ${ }^{37}$ however, the longterm performance still needs to be evaluated. A TEHV like the TexMi reproducing the main mitral valve components, has the potential advantage of being a living implant with remodeling capabilities, which will last for a lifetime without the need for reintervention, ${ }^{16,17}$ it is not thrombogenic, does not deteriorate by calcification, and preserves the ventricular function by chordae tendineae.

Fibrin-based cardiovascular tissue-engineered constructs have shown promising results. Fibrin-based TEHVs implanted in the pulmonary circulation of the sheep model have shown the absence of thromboembolism, hemorrhagic complications, calcifications, stenosis, rejection, and transmission of infection. $^{23,24}$ Furthermore, complete in vivo ${ }^{23}$ and in vitro ${ }^{38}$ endothelialization of fibrin-based tissue-engineered constructs providing optimal hemocompatibility has also been shown and the application of a textile-reinforced fibrin-based vascular graft in the arterial circulation has been demonstrated. ${ }^{25}$ These results, together with the ease of fabrication, the functionality, and the considerable ECM synthesis shown for the TexMi in this article, are encouraging toward the realization of a tissueengineered textile-reinforced mitral valve with (1) shape mimicking the native 3D valvular anatomy, (2) preservation of the myocardial function through the chordae tendineae, (3) physiological hemodynamics, (4) physiological hemocompatibility, (5) adequate mechanical properties to withstand the high stress of the systemic circulation, and (6) remodeling and self-repair capability. Further possible variations to the presented method and subjects of ongoing investigation include a different leaflet geometry, the optimization of the mesh in terms of pore size and material, optimization of the conditioning protocol, and identification of an optimal cell source for the human case.

\section{Acknowledgments}

The authors gratefully acknowledge the financial support of the Max-Buchner-Forschungsstiftung. The research leading to these results has received funding from the People Programme (Marie Curie Actions) of the European Union's Seventh Framework Programme FP7/2007-2013/under REA grant agreement 317512 .

\section{Disclosure Statement}

No competing financial interests exist.

\section{References}

1. Yacoub, M.H., and Takkenberg, J.J.M. Will heart valve tissue engineering change the world?. Nat Clin Pract Cardiovasc Med 2, 60, 2005.

2. Iung, B., and Vahania, A. Epidemiology of valvular heart disease in the adult. Nat Rev Cardiol 8, 162, 2011.

3. Iung, B., Baron, G., Butchart, E.G., Delahaye, F., GohlkeBarwolf, C., Levang, O.W., Tornos, P., Vanoverschelde, J.L., Vermeer, F., Boersma, E., Ravaud, P., and Vahanian, A. A prospective survey of patients with valvular heart disease in Europe: the Euro Heart Surgery on Valvular Heart Disease. Eur Heart J 24, 1231, 2003.

4. Loyd-Jones, D., Adams, R.J., and Brown, T.B. Heart disease and stroke statistics-2010 update: a report from American Heart Association. Circulation 121, 46, 2010.

5. Yacoub, M.H., and Cohn, L.H. Novel approaches to cardiac valve repair: from structure to function: part II. Circulation 109, 1064, 2004.

6. Zhao, L., Kolm, P., Borger, M., Zhang, Z., Lewis, C., Anderson, G., Jurkovitz, C.T., Borkon, A.M., Lyles, R.H., and Weintraub, W.S. Comparison of recovery after mitral repair and replacement. J Thorac Cardiovasc Surg 133, 1257, 2007.

7. David, T.E., Ivanov, J., Armstrong, S., Christie, D., and Rakowski, H. A comparison of outcomes of mitral valve repair for degenerative disease with posterior, anterior, and bileaflet prolapsed. J Thorac Cardiovasc Surg 130, 1242, 2005.

8. Gammie, J.S., Zhao, Y., Peterson, E.D., O'Brien, S., Rankin, J.S., and Griffith, B.P. Less invasive mitral valve operations: trends and outcomes from the Society of Thoracic Surgeons Adult Surgery Database. Ann Thorac Surg 90, 1401, 2010.

9. Gummert, J.F., Funkat, A.K., Beckmann, A., Ernest, M., Hekmat, K., Beyersdorf, F., and Schiler, W. Cardiac surgery in Germany during 2010: a report on behalf of the German Society for Thoracic and Cardiovascular Surgery. Thorac Cardiovasc Surg 59, 259, 2011.

10. El Oakley, R., Kleine, P., and Bach, D.S. Choice of prosthetic heart valve in today's practice. Circulation 117, 253, 2008. 
11. Reul, H., Talukder, N., and Mueller, E. W. Fluid mechanics of the natural mitral valve. J Biomech 14, 361, 1981.

12. Reardon, M.J., and David, T.E. Mitral valve replacement with preservation of the subvalvular apparatus. Curr Opin Surg 14, 104, 1999.

13. Misfeld, M., and Sievers, H. Heart valve macro- and microstructure. Phil Trans R Soc B 362, 1421, 2007.

14. Bloomfield, P. Choice of Heart Valve Prosthesis. Heart 87, 583, 2002.

15. Natsuaki, M., Itoh, T., Tomita, S., Furukawa, K., Yoshikai, M., Suda, H., and Ohteki, H. Importance of preserving the mitral subvalvular apparatus in mitral valve replacement. Ann Thorac Surg 61, 585, 1996.

16. Vesely, I. Heart valve tissue engineering. Circ Res 97, 743, 2005.

17. Schoen, F.J. Heart valve tissue engineering: quo vadis?. Curr Opin Biotechnol 22, 698, 2011.

18. Butcher, J.T., Mahler, G.J., and Hockaday, L.A. Aortic valve disease and treatment: the need for naturally engineered solutions. Adv Drug Deliv Rev 63, 242, 2011.

19. Mol, A., Smits, A.I.P.M., Bouten, C.V.C., and Baaijens, F.P.T. Tissue engineering of heart valves: advances and current challenges. Expert Rev Med Devices 6, 259, 2009.

20. Cholewinski, E., Dietrich, M., Flanagan, T.C., SchmitzRode, T., and Jockenhoevel, S. Tranexamic acid-an alternative to aprotinin in fibrin-based cardiovascular tissue engineering. Tissue Eng Part A 15, 3645, 2009.

21. Dietrich, M., Heselhaus J., Wozniak, J., Weinandy, S., Mela, P., Tschoeke, B., Schmitz-Rode, T., and Jockenhoevel, S. Fibrin-based tissue engineering: comparison of different methods of autologous fibrinogen isolation. Tissue Eng Part C Methods 19, 216, 2013.

22. Jockenhoevel, S., Chalabik, K., Sachweh, J.S., Groesdonk, H.V., Demircan, L., Grossmann, M., Zund, G., and Messmer, B.J. Tissue engineering: complete autologous valve conduit-a new moulding technique. Thorac Cardiovasc Surg 49, 287, 2001.

23. Flanagan, T.C., Sachweh, J.S., Frese, J., Schnoring, H., Gronloh, N., Koch, S., Tolba, R.H., Schmitz-Rode, T., and Jockenhoevel, S. In vivo remodeling and structural characterization of fibrin-based-tissue-engineered heart valves in the adult sheep model. Tissue Eng Part A 15, 2965, 2009.

24. Syedain, Z., Lathi, M., Johnson, S.L., Robinson, P., Ruth, G.R., Bianco, R., and Tranquillo, R.T. Implantation of a tissue-engineered heart valve from human fibroblasts exhibiting short term function in the sheep pulmonary artery. Cardiovasc Eng and Technol 2, 101, 2011.

25. Koch, S., Flanagan, T.C., Sachweh, J.S., Tanios, F., Schnoering, H., Deichmann, T., Ella, V., Kellomaki, M., Gronloh, N., Gries, T., Tolba, R., Schmitz-Rode, T., and Jockenhoevel, S. Fibrin-polylactide-based tissue-engineered vascular graft on the arterial circulation. Biomaterials 31, 4731, 2010.

26. Barber, J.E., Ratliff, N.B., Cosgrove, D.M., Griffin, B.P., and Vesely, I. Myxomatous mitral valve chordae. I: mechanical properties. J Heart Valve Dis 10, 320, 2001.

27. Ranganathan, N., Lam, J.H.C., Wigle, E.D., and Silver, M.D. Morphology of the human mitral valve: II. The valve leaflets. Circulation 41, 459, 1970.

28. Muresian, H. The clinical anatomy of the mitral valve. Clin Anat 22, 85, 2009.

29. Reddy, G.K., and Enwemeka, C.S. A simplified method for the analysis of hydroxyproline in biological tissues. Clin Biochem 29, 225, 1996.
30. Mol, A., Rutter, M.C.M., Driessen, N.J.B., Bouten, C.V.C., Zünd, G., Baaijens, F.P.T., and Hoerstrup, S.P. Autologous human tissue engineered heart valves: prospects for systemic application. Circulation 114, 152, 2006.

31. Patel, A., Fine, B., Sandig, M., and Mequanint, K. Elastin biosynthesis: the missing link in tissue-engineered blood vessels. Cardiovasc Res 71, 40, 2006.

32. Gauvin, R., Guillemette, M., Galbraith, T., Bourget, J., Larouche, D., Marcoux, H., Aubé, D., Hayward, C., Auger, F., and Germain, L. Mechanical properties of tissueengineered vascular constructs produced using arterial or venous cells. Tissue Eng Part A 16, 2049, 2011.

33. Ratner, B.D., Hoffman, A.S., Schoen, F.J., and Lemons, J.E. Biomaterials Science: An Introduction to Materials in Medicine. Amsterdam: Elsevier, 2004.

34. Sri Harwoko, M., Budillon, F., Aibibu, D., and Gries, T. Medical textiles for tissue engineering. Paper presented at the $5^{\text {th }}$ International Conference Focusing on Polymers Used in the Medical Industry, Cologne, Germany, 2006. Paper no. 13.

35. Daebritz, S.H., Sachweh J.S., Hermanns, B., Fausten, B., Franke, A., Groetzner, J., Klosterhalfen, B., and Messmer, B.J. Introduction of a flexible polymeric heart valve prosthesis with a special design for mitral position. Circulation 108, 134, 2003.

36. Walther, T., Walther, C., Falk, V., Langebartels, G., Krueger, M., Dagge, A., Diegeler, A., Autschbach, R., and Mohr, F.W. Quadrileaflet stentless mitral valve replacement. Thorac Cardiovasc Surg 47, 357, 1999.

37. Hofmann, B., Cichon, R., Knaut, M., Kappert, U., Tugtekin, S.M., Aron, W., and Schueler, S. Early experience with a quadrileaflet stentless mitral valve. Ann Thorac Surg 71, 323, 2001.

38. Weinandy, S., Rongen, L., Schreiber, F., Cornelissen, C., Flanagan, T.C., Mahnken, A., Gries T., Schmitz-Rode, T., and Jockenhoevel, S. The BioStent: novel concept for a viable stent structure. Tissue Eng Part A 18, 1818, 2012.

Address correspondence to: Petra Mela, PhD

Department of Tissue Engineering and Textile Implants Institute of Applied Medical Engineering Helmholtz Institute RWTH Aachen University Pauwelsstr. 20 Aachen 52074 Germany

E-mail: mela@hia.rwth-aachen.de

Stefan Jockenhoevel, MD Department of Tissue Engineering and Textile Implants Institute of Applied Medical Engineering Helmholtz Institute

RWTH Aachen University Pauwelsstr. 20 Aachen 52074 Germany

E-mail: jockenhoevel@hia.rwth-aachen.de

Received: July 12, 2013

Accepted: January 6, 2014

Online Publication Date: March 25, 2014 